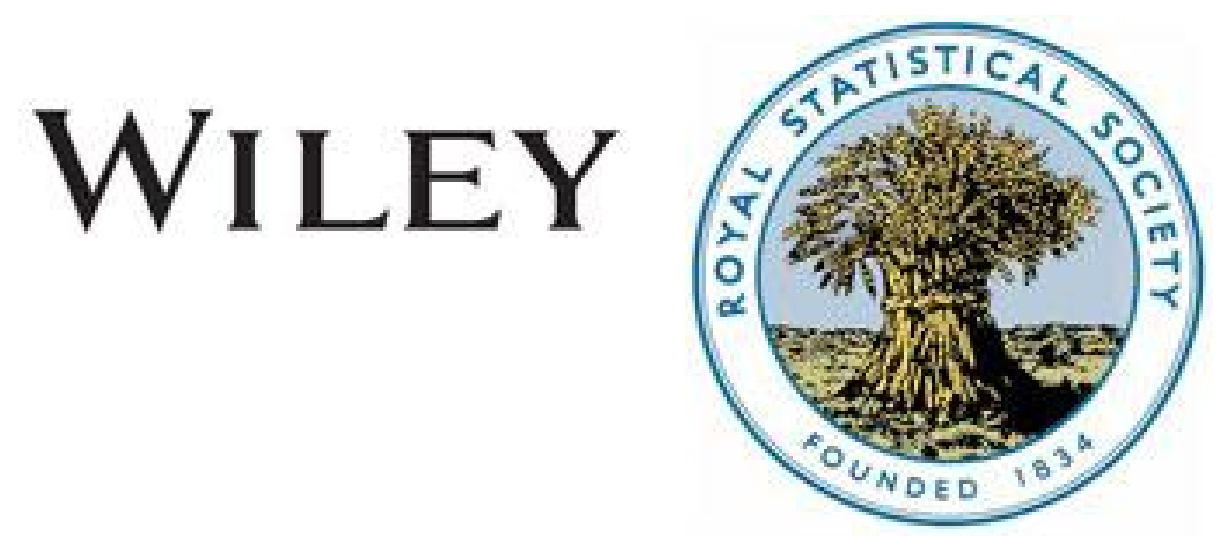

On the Representation of Certain Examination Results in Two and in Three Dimensions Author(s): W. Garnett

Source: Journal of the Royal Statistical Society, Vol. 73, No. 1 (Jan., 1910), pp. 1-9

Published by: Wiley for the Royal Statistical Society

Stable URL: http://www.jstor.org/stable/2340009

Accessed: 27-06-2016 05:32 UTC

Your use of the JSTOR archive indicates your acceptance of the Terms \& Conditions of Use, available at

http://about.jstor.org/terms

JSTOR is a not-for-profit service that helps scholars, researchers, and students discover, use, and build upon a wide range of content in a trusted digital archive. We use information technology and tools to increase productivity and facilitate new forms of scholarship. For more information about JSTOR, please contact support@jstor.org.

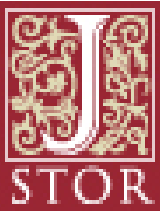

Wiley, Royal Statistical Society are collaborating with JSTOR to digitize, preserve and extend access to Journal of the Royal Statistical Society 


\title{
JOURNAL
}

\section{OF THE ROYAL STATISTICAL SOICETY.}

\author{
JANUARY, 1910.
}

\section{On the Representation of Certain Examination Results in Two and in Three Dimensions.}

\author{
By Dr. W. Garnett, M.A.
}

[Read before the Royal Statistical Society, December 14, 1909.]

IN the spring of 1909 rather more than 20,000 children were presented for the Junior County Scholarship Examination conducted by the Education Committee of the London County Council. The children were all drawn from the public elementary schools of London; they were all between 11 and 12 years of age on the 31 st July last; and they had practically all reached the Vth or higher standard. In some cases the boys and girls had been taught in mixed schools by men or women indiscriminately. In the majority of cases the boys had been drawn from boys' departments taught by men, and the girls from girls' departments taught by women. No attempt has at present been made to separate the results of the examination according as the children came from boys', girls' or mixed departments or were taught by men or women. In the examination the papers were the same for all candidates. A large number of examiners were employed-some men, some women-all marking in accordance with the standards laid down by the Chief Examiner, and the papers were distributed indiscriminately among the examiners. As there were in round numbers 10,000 boys and I०,000 girls, drawn from considerably more than $\mathrm{r}, 000$ school departments, and taught at the time by about 3,000 separate teachers, it may be fairly considered that accidents due to individuals have been almost eliminated from the examination results.

The examination comprised a paper upon arithmetic intended as a test of intelligence, with a second part consisting of problems requiring some thought; a story which the children were allowed to read and afterwards to write out in their own language, with a few questions intended to test their understanding of the story; and, in addition, some simple questions to test the children's power of observation and of describing common things as well as their

VOL. LXXIII. PART I. 
ability to make simple sentences containing words the meanings of which were well known to them. Marks were given for writing, spelling and composition. The examination thus consisted of two parts-namely, arithmetic and English, roo marks being assigned to each.

From the reports of the examiners and the statistical tables which they submitted, it seemed clear that there was a distinct difference between the boys and the girls with regard to their relative power of dealing with the English portion and the arithmetical portion of the examination. In order to test this further, I constructed separate correlation diagrams for boys and for girls, the English marks being set out horizontally and the arithmetic marks vertically. The marks gained by each candidate were indicated by a dot placed on the diagram, the co-ordinates of which corresponded to the marks in English and arithmetic respectively; but for this purpose the marks in each subject were grouped in tens, so that the diagrams consisted of roo squares. At the time the diagrams were made, not quite all the mark sheets were available, and the diagrams shown indicate the results from 10,105 boys and 9,396 girls. The method of construction was the following :-The mark sheets for the boys and the girls were each divided into about half a dozen groups, and in the first instance a diagram was made for each group, in order that the number of dots in any square should not be more than could be conveniently inserted in a halfinch square and afterwards counted. The number of dots in each square was counted, and transferred in Arabic figures to a new diagram. The numbers in each set of six diagrams were then added together, and from these numbers the final diagrams shown in Figs. 1 and 2 were made. In order to insert the dots symmetrically in each square, a number was selected of the form of $n^{2}$ or $n(n+1)$ approximating as nearly as possible to the actual number. The dots were then set out in $n$ rows and $n$ columns or $n$ rows and $n+1$ columns as the case might be, a few additional dots being inserted or a few dots omitted more or less symmetrically so as to secure the exact number of dots required. The chief features of the correlation diagrams are apparent to the eye by the toning afforded through the varying density of the dots. The diagrams in fact form a half-tone illustration, differing from an ordinary half-tone print prepared from a screen negative by the toning being caused by the variation in the number of dots per square inch instead of their magnitude. It will be observed that upon each diagram the diagonal line drawn upwards from left to right corresponds to equal marks in English and arithmetic. All the candidates who lie below this diagonal obtain more marks 
in English than in arithmetic ; those above it obtain more marks in arithmetic than in English. The diagrams show at once that the weaker candidates on the whole did better in English than in arithmetic, and the stronger candidates did better in arithmetic than in English.

Lines of equal merit, as estimated by the sum of the marks, are lines parallel to the diagonal of the square sloping downwards from the left. If we draw a series of straight lines in this direction the numbers contained in the several squares indicate the distribution of the candidates between arithmetic and English when their merit, as gauged by the sum of the marks, is the same. If on each of these lines we select the square in which the number is the greatest, we obtain a series of modes indicating the position of the greatest number of candidates of each standard (differing by ro marks on the total of 200) of total merit. The modes thus determined differ very slightly from those obtained either from the horizontal rows or vertical columns, that is, by considering the positions of the candidates in English who obtain equal marks in arithmetic or the position of the candidates in arithmetic who obtain equal marks in English. For the purpose of the

Marks gained by 10,1 105 boys.

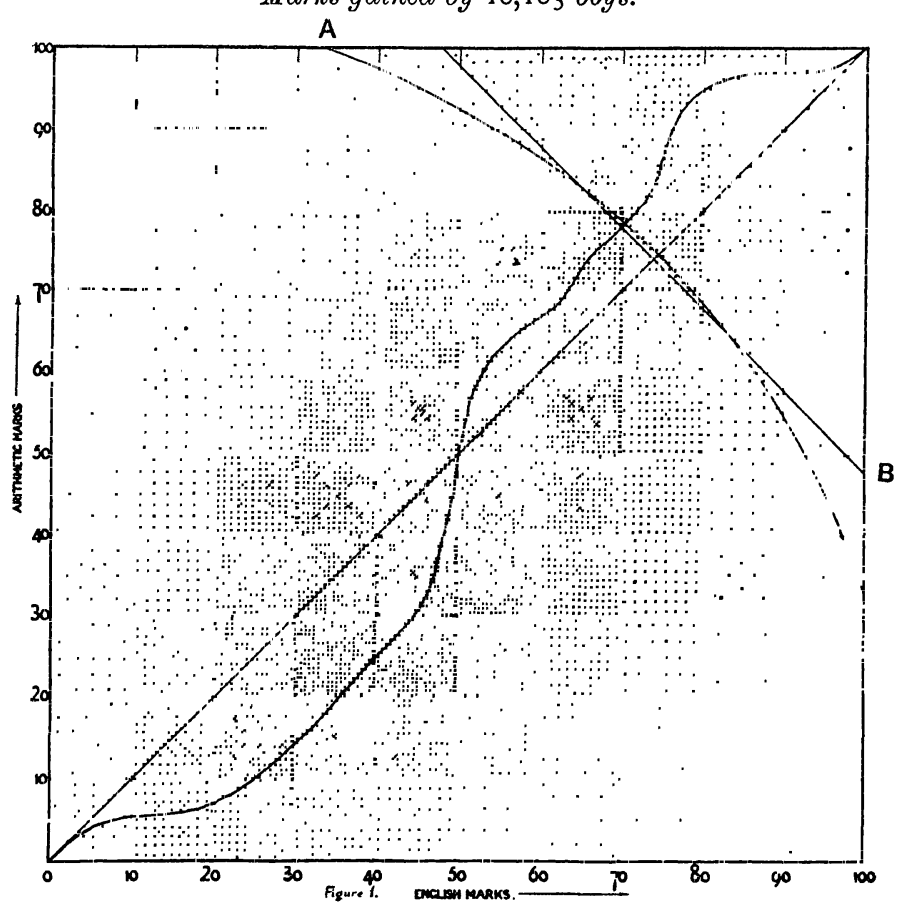

B 2 
Marks gained by 9,396 girls.

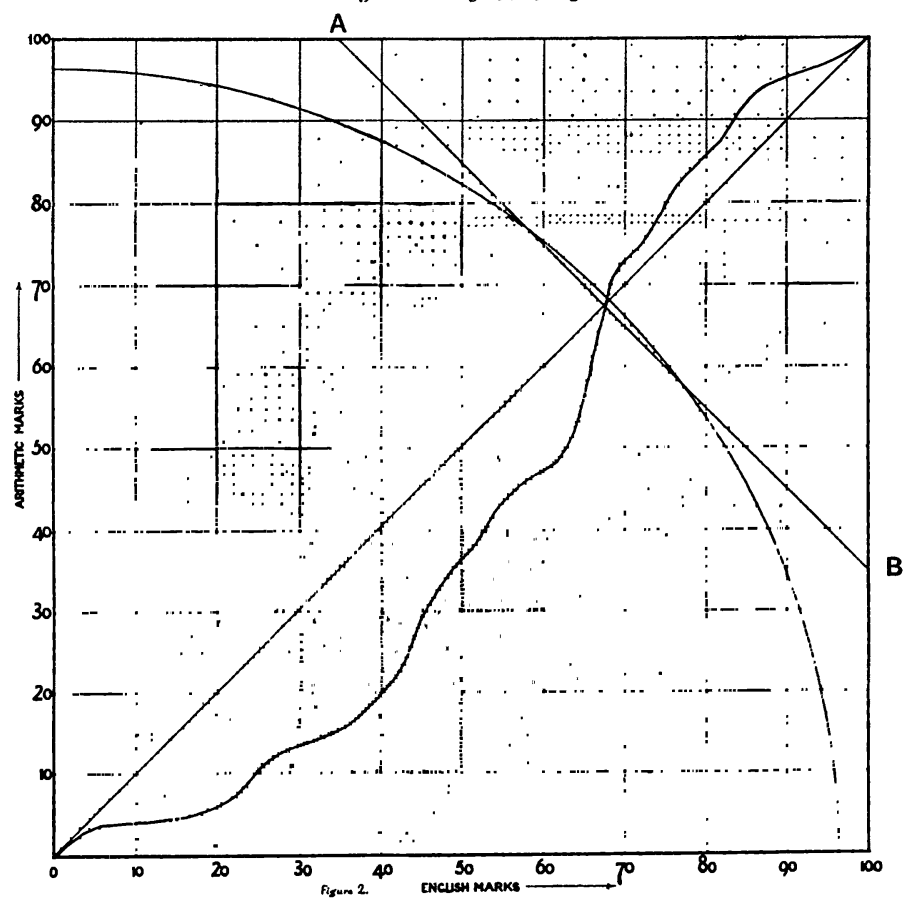

comparison it seemed best to deal with candidates of equal merit in the whole examination. The smooth curve drawn through these modes is shown on each diagram by the irregular line. In smoothing off this curve regard has been had to the slope of the numbers along each line of equal merit, so that when the numbers contained in two squares were very nearly equal the line has been drawn within the square containing the largest number, but very near to the boundary separating it from the square containing the next largest. It will be observed that in the diagram relating to the boys this line of modes cuts the line of equal merit at, or very near, the centre of the whole diagram. That is to say, when boys gain more than half marks in the whole examination they begin to do better as a whole in arithmetic than in English, but those who gain less than half marks in the whole examination do better as a whole in English than in arithmetic. In the case of the boys, about 42 per cent. lie above the intersection of the line of modes with the line of equal merit in the two subjects. The line $\mathrm{AB}$, corresponding to 147 marks in the whole examination, cuts off the best 800 candidates, and this line will be called the line of distinction. In the case of the girls the line $\mathrm{AB}$ which cuts off the best 800 girls corresponds to a 
total of 135 marks; and it will be observed that the line of modes does not cut the line of equal merit until it has passed beyond this line, so that it is only among the highest 7 per cent. or $7 \frac{1}{2}$ per cent. of the girls that the majority do better in arithmetic than in English. This peculiarity in the line of modes in the two diagrams seems to indicate a distinct difference between the boys and girls either in their natural ability to deal with the two subjects or in the character of the training which they have received. It seems desirable that, in future examinations, similar diagrams should be made separately for boys who have been taught by men, boys who have been taught by women, girls who have been taught by men, and girls who have been taught by women; and it might also be interesting to make additional diagrams for boys and girls separately who have been taught in mixed classes, whether by men or by women. It seems probable that much of the difference is due to traditional forms of teaching, when it is remembered that the standard required by the Board of Education in arithmetic in the certificate examination is different for men and for women, and that for some hundreds of years the practice of the elementary school was to teach boys the keeping of accounts, but in place thereof to teach girls needlework.

Having prepared the two-dimensioned diagrams, it occurred to me that their peculiarities would be more clearly presented to the eye by a solid model, and I accordingly constructed two models in which the ordinates represent the numbers in the corresponding squares of the diagrams on the scale of roo candidates to the inch. These models are shown in Figs. 3 and 4 in isometric projection.

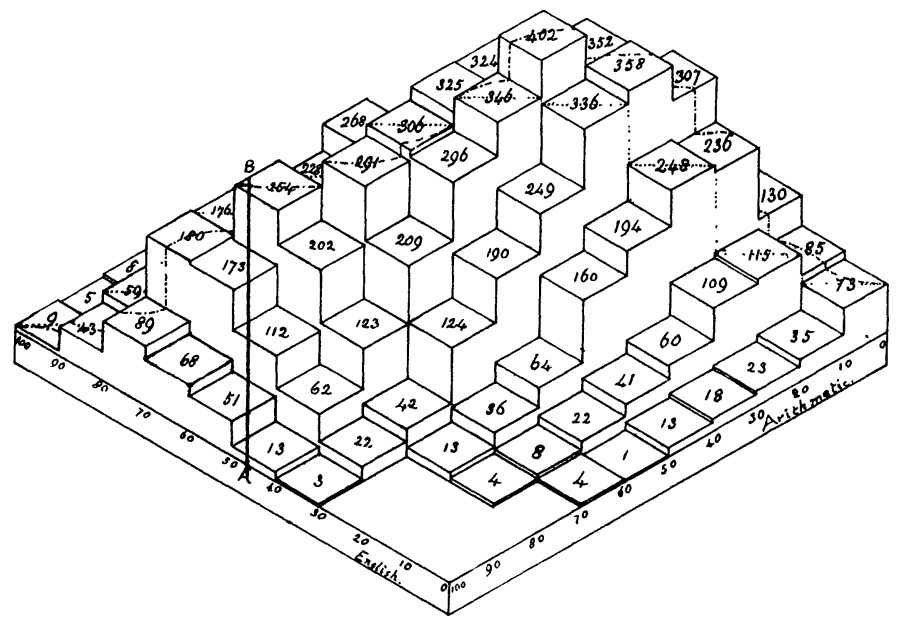

Figure 3.-10, I05 boys. 


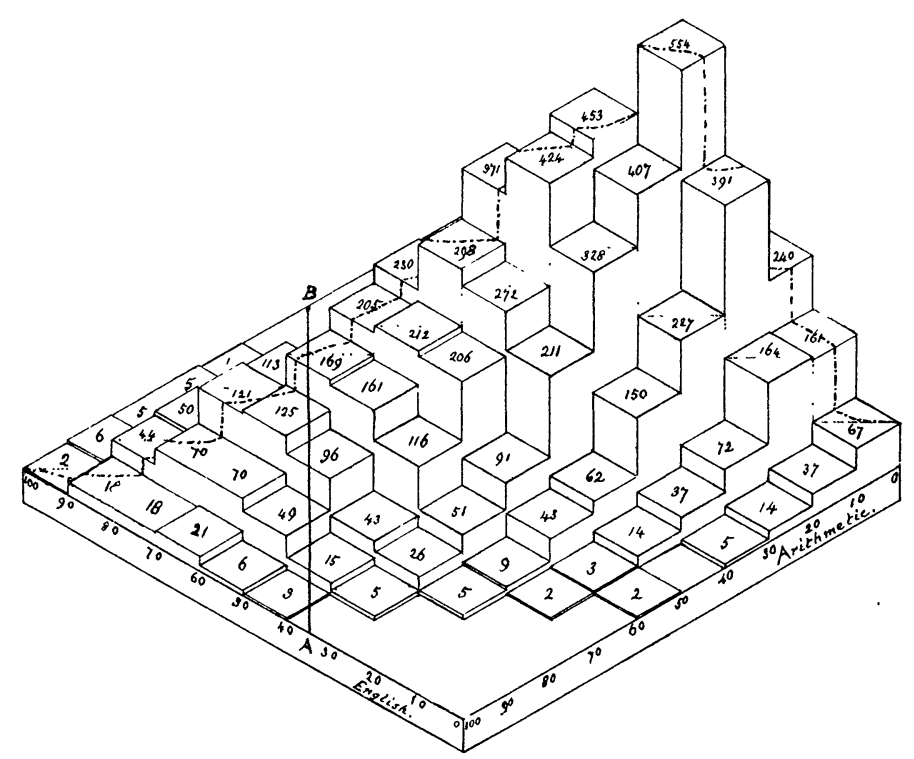

Figure 4.-9.396 girls.

To give the most characteristic view of the models they have been turned so that the point corresponding to full marks in arithmetic and zero marks in English is nearest to the observer. The planes of equal merit, gauged by the sum of the marks, appear as vertical straight lines, of which the line $A B$ is an example. The great differences between the boys and girls are brought out prominently by the forms of the two mountain masses, and it will be noticed how nearly all the peaks in the girls' model lie on the English side of the dotted line of equal marks in the two subjects, and how low that line lies upon the mountain slope. The concave profile from the highest peak to the point corresponding to full marks in the girls' model contrasts very markedly with the convex profile in the boys' model. On the models the line of modes, shown in Figs. 3 and 4 by the broken line, forms what the geographers would call a watershed or divide, the surface sloping downwards both to the right and left as we travel along the line. It should further be noted that the difference between the relation of the line of modes to the line of equal marks in the two subjects on the two models is much more conspicuous than on the twodimensioned diagrams. A mere glance at the models suggests that there must be some essential difference between boys and girls in their training, or in their natural ability to deal with English and arithmetic.

At an early stage it occurred to me that if, in dealing with two 
such diverse subjects as arithmetic and English, lines of equal merit were taken as circles on the correlation diagram, having their centre at the zero point, so that the total marks were reckoned as $\sqrt{x^{2}+y^{2}}$ instead of $x+y$, the difficulty so commonly felt by examiners in dealing with scrappy marks in one subject would be eliminated automatically, as 80 marks in arithmetic and ro in English would count only as 80.6, while 80 marks in English and 20 in arithmetic would count as 82.4 , and full marks in one subject would be $70^{\circ} 7$ per cent. instead of 50 per cent. of the total. I therefore drew upon the dotted diagrams the circles shown in Figs. 1 and 2, so as to cut off 800 candidates, the same number as were cut off by the line $\mathrm{AB}$, which I have called the line of distinction. The result was that both in the case of the boys and of the girls only i9 candidates were exchanged. It seems, therefore, that in dealing with candidates of the average age of $\mathrm{II} \frac{1}{2}$ from the elementary schools the correlation between English and arithmetic is such that the sum of the marks serves sufficiently well for defining the merit of the candidates. In the case of older candidates, where specialisation is so much more marked that the correlation coefficient may even be negative, the difference between the circles and the straight lines would have been much greater in respect of the number of candidates affected. It may fairly be contended that when a competitive examination comprises a number of different subjects the marks should be added as vectors, the direction of which depends on the nature of the subject. When the subjects are closely related, the vectors should be nearly in the same direction; when there is little or no connection between the subjects, the vectors may be at right angles. The main difficulty would be to secure an agreement between the examiners as to the $\theta$ and $\phi$ of their several subjects.

The position of several of the candidates who were very near the line of distinction was considered, not only in connection with the marks gained in the examination, but also in relation to their school reports, based largely on the results which they had achieved in former school examinations. It occurred to me to ascertain to what extent the school records introduced the is specialists, who in each case would have come into the first 800, if the circle instead of the straight line had been adopted. To ascertain this I plotted the positions of all these (andidates accurately to half a mark. I found that, especially among the girls, the candidates thus brought in were those who did approxi. mately equally well in the two subjects. In other words, specialisation is not favoured in the elementary schools among children of the age of $1 \times \frac{1}{2}$. Perhaps this is as it should be. 


\section{Discussion on Dr. Garnett's Paper.}

Mr. Yule said that, as he was partly responsible for the reading of Dr. Garnett's paper before the Society, he would like to express his appreciation of and interest in the results. $\mathrm{He}$ had never seen any diagram which brought out similar curious results of examinations in different subjects. $\mathrm{He}$ could not attempt to suggest reasons for the curious differences between boys and girls in the marks obtained in arithmetic and English; but they were certainly in the direction one would have expected. One was accustomed to the boy who could do well at arithmetic, but whose English was hopeless; and also to the girl whose English might be quite competent, but whose arithmetic was hopeless. Further, as the results were obtained from such a large number of examinees, the result was definite and trustworthy. The difference in form between the two models was especially marked. In the case of the girls, the whole mass of the returns was crowded very much more closely round the central line of the model; the correlation was higher. In the case of boys it was rather lower. He wished those principal forms of difference could be explained in some way. The whole result suggested a wide vista in the discussion of examination results and the differences they indicated between boys and girls. But he would like to know whether they were the results of the number of marks obtained by a number of different Examiners, so as to cut out fairly personal equation.

Dr. GARNETT said there were a large number of Exaniners, but they all examined under strict rules as to the manner in which they should deal with the errors, all of which could be foretold when dealing with such simple questions with a large number of candidates. All the results passed through the hands of the Chief Examiner afterwards.

Mr. YULE said in that case they might regard the personal equation of the Examiner as eliminated; and there remained only the personal idiosyncrasies of the candidates.

Mr. Sydney Young said his personal experience rather differed from the result shown. He had been educated at a mixed school. Notwithstanding that the girls were fewer in number, they generally obtained higher places in the class on all subjects. That might be due to the girls being of a better class than those treated of by Dr. Garnett. Certainly the girls generally obtained higher places in the classes. They did not, however, get the highest place, which was obtained by the boys, and they tended to deteriorate at the age of 14 or so, both mentally and physically. He did not know whether it was a question of better heredity. 
The President, in proposing a vote of thanks to Dr. Garnett for his communication, said he hoped this would not be the author's last appearance among them. It seemed to him that the subject required a considerable amount of investigation on the lines Dr. Garnett had indicated. They had at present the mere outline expressed in three dimensions, which was exceedingly instructive, but made it clear they had to investigate the psychology not only of the pupils but of the teachers. If they could differentiate the results, as tested by examination, of teaching at different centres, of different classes, by different sexes, and, generally, under different conditions, they would have a much more instructive result even than the one presented. 